\title{
Implementing Revenue Management for Travel Agencies
}

\author{
Grace Suk Ha Chan ${ }^{1} \&$ Basak Denizci Guillet ${ }^{1}$ \\ ${ }^{1}$ School of Hotel and Tourism Management, The Hong Kong Polytechnic University, Hong Kong SAR \\ Correspondence: Grace Chan, School of Hotel and Tourism Management, The Hong Kong Polytechnic University, \\ Hong Kong SAR. Tel: 852- 5692-6005. E-mail: gracechansh@hotmail.com
}

Received: May 10, $2015 \quad$ Accepted: September 28, $2015 \quad$ Online Published: November 30, 2015
doi:10.5539/jms.v5n4p17

\begin{abstract}
The purpose of this descriptive study is to explore revenue management (RM), it may relevant for travel agencies in their business management. In view of the features that this sector shares with traditional revenue management (RM) users such as the airline and hotel industries, travel agencies have the potential to enhance revenue by applying various RM techniques. Both traditional and non-traditional users of RM have benefitted greatly from the use of RM strategies. In particular, revenue per available tour product (RevPATP) is invoked, both in the present modified typology of RM and in developing RM strategies for the travel sector. The study utilized data from in-depth interviews with industry professionals to determine their perceptions of RM and understand their comments about the possibility of RM implementation in travel agencies. The study's results reveal that travel agencies have limited knowledge of RM, limiting themselves to profit maximization alone. Although the professionals interviewed were aware of the unpredictable nature of the environment in which they operated, most believed that only large travel agencies were capable of applying RM to their operations.
\end{abstract}

Keywords: revenue, yield management, travel agencies, revenue optimization, Hong Kong

\section{Introduction}

Today's highly unpredictable and competitive business environment has profoundly influenced the travel industry. Many travel agencies either are having financial difficulties or have gone out of business because of increases in operating costs such as labor and leases (Hermes Management Consulting, 2008). Struggling travel agencies must increase their margins while simultaneously satisfying their customers in an increasingly fragmented environment (Hermes Management Consulting, 2008). People perceive the world economy as chaotic, which makes consumers more budget-conscious when buying tourism products. Most travel agencies still rely on selling airline tickets, hotel packages and group tours to generate revenue, despite their very low margins.

To survive in this uncertain environment, travel agencies need to adopt advanced operational management methods, among which revenue management (RM) may be the most suitable. The purpose of this study is not to outline how revenue management works but rather to examine the possibility that RM could be integrated into the business management practices of Hong Kong travel agencies. Many companies in the service industry, ranging from hotels and rental car agencies to restaurants, have adopted RM practices that involve information systems and pricing strategies to manage customer flow and allocate the right capacity for the right customer at the right place and time (Kimes, 2000).

Past scholars have focused exclusively on the successful application of RM in the hospitality sector, ignoring the travel agency sector. However, given the competitive environment in Hong Kong, travel agencies must implement RM if they want to address their shrinking profits (Berman, 2005; Chiang et al., 2007; Cross, 1997; Kimes, 2000; Kimes \& Singh, 2009; Marcus \& Anderson, 2008; Noone \& Mattila, 2009; Sun et al., 2011; Upchurch et al., 2002).

\subsection{Hong Kong Travel Agencies' Problems}

In a rapidly changing business environment, the two major perceived threats are the disintermediation of retail agencies by primary producers and the emergence of new virtual intermediaries (Barnett \& Standing, 2000). The profit margins of travel agencies in Hong Kong are suffering from downward industry price trends, higher operating costs, reduced supplier commissions and global economic uncertainties (Law \& Wong, 2003). The rapid growth of online reservations has similarly led to a decline in traditional indirect tourism intermediary 
channels (Law \& Wai, 2001; Law \& Wong, 2003; Pak \& Piersma, 2002; Wardell, 1998).

Higher operating costs have placed financial constraints on small and undercapitalized firms; the implementation of a statutory minimum wage in Hong Kong on 1 May 2011 increased travel agencies' labor costs. Subsequently, smaller independent agencies have found it more difficult to make adjustments in their businesses (Minimum Wage Commission, 2012). According to the Travel Agent Registry, travel agencies generally shut down for commercial reasons, conflicting views on business strategies among their partners or unfavorable external economic environments (Travel Agents Registry, 2013). These travel agencies largely closed down because of ineffective business strategies. Given the number that have closed in recent years, medium-to-small travel agencies face a difficult financial situation (Hong Kong Tourism Commission, 2012), from an uncertain economic environment to having their middleman positions cut by suppliers.

\subsection{The Business Model in Hong Kong in the Travel Agencies}

Travel agents are distinct from other members of the tourism sector because they sell various tourism products on behalf of suppliers. Travel agencies provide labour-intensive clerical activities on behalf of airlines, such as ticket processing and fare provision (Lubbe, 2005), and because they do not carry stock they bear little financial risk. Travel agencies do not purchase products or services, but act on behalf of consumers and receive commissions on sales from their suppliers (i.e., from the principals on whose behalf they act as agents). This means that the sales contract is not between the customer and the travel agent, but between the customer and the principals (hotels or airlines). In this context, the role of travel agencies loses importance. In addition, suppliers can exchange strategies with travel agencies and reduce their incentives.

The majority of travel agencies in Hong Kong are small and medium-sized enterprises (SMEs) that are run privately or by a family (Information Service Department, HKSAR Government, 2012). SME travel agencies can be considered weak because they are threatened by the uncertainties in their operating environment and decreases in market shares and profit levels.

During economic downturns, demand is lower and market prices tend to decrease. Thus, adding value to the service is more reasonable than cutting costs. To survive in a competitive market, Hong Kong travel professionals should pay attention to advanced operational methods and refer to the RM studies conducted by various scholars (Yeoman \& Ingold, 1997; Anderson \& Xie, 2009; Anderson \& Marcus, 2007; Lubbe, 2005; Dacko, 2004) for ways in which RM might help them survive in this changing market.

Hong Kong travel agencies, which are more likely to be small or medium-sized, sell airline tickets, hotel room arrangements and packaged tours. Tour wholesalers and retailers, which are typically medium-sized to large agencies, sell outbound group tours and provide outbound business and packages. International travel agencies fall under the large group and belong to multinational companies that provide inbound services and offer inbound travel and packages. A number of online travel agencies in Hong Kong conduct reservations through online arrangements involving local and overseas hotels.

Travel agencies largely function as intermediaries between the primary creators/suppliers of travel products and consumers (Barnett \& Standing, 2000). Over the last decade, many supply chains such as airlines and hotels have come under pressure as consolidators market their available products directly to consumers. Thus, the travel agencies' revenue has shifted to their suppliers, with the former offering a wide range of product choices from different suppliers. It is crucial to adopt relevant RM for travel agencies to cope with the business decision making.

In the previous studies, little research and few books have been published that consider travel agencies. Thus, the goals of this descriptive research study are to obtain more information on and examine whether RM may be relevant for travel agencies. Specifically, this research has the following objectives:

- To examine the extent and nature of RM practices among selected travel agencies in Hong Kong;

- $\quad$ To examine travel agents' perceptions of RM \&

- $\quad$ To identify the barriers to and facilitators of RM implementation among Hong Kong travel agencies.

To implement a formal (RM) system, travel agencies need a solid foundation of information to optimise revenue for each product. With the right strategies, RM systems can help travel agencies to come up with right decision making. 


\section{Literature Review}

\subsection{Developing Revenue Management for Travel Agencies}

\subsubsection{Revenue Per Available Tour Product (RevPATP)}

To implement a formal RM system, travel agencies need a solid foundation of information to optimize revenue for each product. With the right strategies, RM systems can provide accurate assessments of past booking patterns and current conditions to help travel professionals make business decisions that result in selling the right product to the right customer at the right price, thereby maximizing travel agency revenue. Travel professionals need to know which guests are the most desirable for their tourism products. This can be determined based on who provides the highest overall revenue in purchasing tourism products from travel agencies. Too often, travel agencies provide unlimited discounts and accept inequitable proportions of lower-paying guests, which decrease profitability.

The hotel industry uses price offers to increase 'revenue per available room' (RevPAR) based on yield management analyses (Kimes et al., 1998). The key factors in determining room revenue are average room rate and occupancy. Travel agencies can calculate a performance metric by dividing customer revenue from different tourism products in different periods. They should thus focus on 'revenue per available tour product' (RevPATP) to maximize each product for profit making. The key factors in determining tour product revenue are the average expenditure per customer in a group and a pre-fixed group size in the tour product.

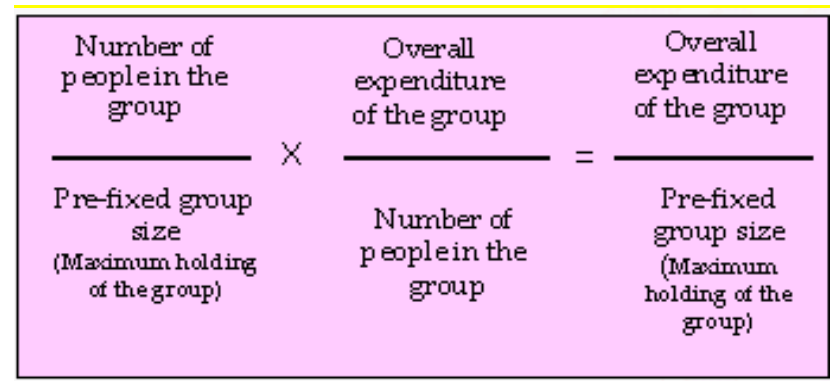

Figure 1. Revenue per available tour product (RevPATP) for travel agencies

Tour managers often use the total number of customers served, the total expenditures per customer and the rebate commissions from suppliers or mark-up percentages to determine their profits. Travel agencies would benefit from understanding the relationship between the average expenditure for a tour product and that for a group tour. Travel agencies seldom combine the information from the average customer expenditure and the seat availability of each tour product or offering. In determining the seat availability of each tour product, RevPATP is a better indicator of each product's revenue gathering potential and thus an agency's selling performance than is the total of number of customers served. RevPATP indicates the rate at which revenue is generated and captures the trade-off between the expenditures and seat availability of a tour product or offering. For instance, if the number of customers signed up for a tour product or group increases as the average expenditure per customer decreases, then the travel agency achieves lower or the same RevPATP. Conversely, if a travel agency increases customers' average expenditures (e.g., by increasing regular brochure pricing to price elasticity or insensitive customers), it can maintain a similar RevPATP with a slightly lower headcount. The rest of the seats can be offered at various prices to capture pric sensitive customers (e.g., early bird or special discount pricing). The pricing strategies may vary according to the time or day of the reservation.

When price is used as an RM tool, tour managers must think beyond discounts and develop methods for offering options, such as different room categories (harbor view, suites), airport transfers or optional tours with additional items offered through suggestive selling. The goal is to achieve revenue optimization and increase customers' spending. Eventually, once seats are being sold out, the travel agency can reduce the number of risk rooms or seats (prepaid rooms or airlines seats) provided by the suppliers. They can extend the service capacity offered by the suppliers to increase profits.

As travel agencies begin to provide special pricing structures, they can highlight the market's complexity by providing unique pricing and selling high-yield products. Travel agencies can design unique products, such as customized private group tours or charter services, and offer unique pricing to the right customers. They can also separate their products into two types. For group or regular tour offerings, RevPATP can be used to achieve profit 
maximization. To sell air packages (e.g., tickets, hotel rooms), they could bundle more products to reduce the number of risk rooms and extend their service capacity.

Large travel agencies manage two types of contracts: one carries no financial loss if the agency does not sell rooms (non-risk room agreement) and the other involves prepaid rooms (full-risk room agreement). The non-risk room agreements (without prepaid rooms) offer a much lower risk than their full-risk counterparts (with prepaid rooms). Non-risk rooms are available for purchase at a contracted rate and carry no financial obligation, as they are not blocked and are subject to prior sales. Full-risk rooms block a set of rooms, according to an agreement, at a specified price upon arrival. Travel agencies are financially responsible for the full-risk rooms regardless of the packages they sell.

\subsubsection{Identify High and Low RevPATP Periods}

Once travel agencies understand their RevPATP patterns, they can develop strategies for managing high- and low-RevPATP periods. During low RevPATP intervals, tour managers can either try to attract more customers by increasing the purchase or suggestive selling of tourism products to increase their revenues (e.g., additional costs for upgrading the room, extending the stay duration or purchasing additional tours). During high-RevPATP intervals, tour managers can consider limited discounts and charge premium prices to provide high-yield tourism products. They should also use non-refund or full payment policies to guarantee seats to prevent no-shows and last-minute cancellations.

RevPATP can be used at different levels of analysis and for different purposes. Tour managers can choose to develop a best-suited RevPATP period for their operations. To evaluate the effectiveness of the highest RevPATP periods, the Chinese New Year and Christmas holidays, managers may consider requiring a credit card for full payment of reservations. They can also restrict the transfer dates for tourism products and use inventory control to extend suppliers' service capacity during high RevPATP periods. Using risk and non-risk rooms from their suppliers to stimulate demand generates more choice and product range during high RevPATP periods. In low RevPATP periods, such as before and after the Christmas and Chinese New Year holidays, special or discount prices can be offered to customers (e.g., retirees).

\subsection{Conceptual Definitions of Constructs in RM}

Travel agencies have operational characteristics that are similar to those of other firms in the tourism industry that implement RM, supporting the argument that travel agencies should consider adopting RM. In the literature on RM applications, little research and few books have been published that consider travel agencies.

Airlines' use of traditional RM systems has implications for hospitality organizations because they can forecast, overbook, control both seat inventory and pricing and provide details that elaborate on the characteristics of dynamic pricing. Apart from hotels and airlines, nontraditional RM industries include restaurants and spas. Different industries are subject to different combinations of duration control and variable pricing (Kimes et al., 1998). Kimes (1989) suggested that RM practices are applicable when the following conditions predominate:

- $\quad$ Capacity is relatively fixed (limited capacity);

- $\quad$ Demand can be separated into distinct market segments (segmentation);

- Inventory is perishable (perishable inventory);

- $\quad$ The product is sold well in advance of consumption (reservation system);

- $\quad$ Demand fluctuates substantially (shifting demand); and

- Marginal sales costs are low and marginal production costs are high (pricing policy).

The value of RM systems is that they have the potential to increase profits through analytical and systemized information on the customer base, market characteristics and capacity. This potential is effectively achieved through a detailed analysis of the internal and external functional parameters within which the service industry operates.

\subsubsection{RM Typology: Traditional RM}

RM is based on capacity constraints in businesses' service lines. Its success in different industries depends on the effectiveness of controlling demand (Sun et al., 2011), such as hotels and airlines selling their products to different customers at the right time and for the right price. According to Kimes (1989), RM builds on the conceptual framework shown in Table 1. 
Table 1. Typical pricing and duration positioning of selected service industries

\begin{tabular}{|c|c|c|c|}
\hline & \multicolumn{3}{|c|}{ Price } \\
\hline & \multicolumn{2}{|r|}{ Fixed } & Variable \\
\hline \multirow{9}{*}{ Duration } & \multirow{5}{*}{ Predictable } & Quadrant 1 & Quadrant 2 \\
\hline & & Cinemas & Hotels \\
\hline & & Showplaces & Airlines \\
\hline & & Stadiums & Rental cars \\
\hline & & Convention centers & Cruise lines \\
\hline & \multirow{4}{*}{ Unpredictable } & Quadrant 3 & Quadrant 4 \\
\hline & & Restaurants & Continuing care \\
\hline & & Golf courses & Hospitals \\
\hline & & Internet services & \\
\hline
\end{tabular}

Source: Kimes (1989, p. 6).

Various industries offer special combinations of duration control and variable pricing (Kimes et al., 1998). Industries traditionally associated with RM, such as hotels, airlines, car rental firms and cruise lines, can apply various pricing schemes for a product with a specific or predictable duration (Quadrant 2). Cinemas, performing arts centers, arenas and convention centers charge fixed prices for a product of predictable duration (Quadrant 1). Restaurants, golf courses and most Internet service providers charge a fixed price but face a relatively unpredictable duration of customer use (Quadrant 3). The healthcare industry charges variable prices, and the duration is unknown (Quadrant 4). These divisions, however, are not rigid because, in reality, no fixed demarcation exists between the quadrants; an industry may possess attributes from more than one quadrant.

Successful RM applications are generally found in Quadrant 2 industries (such as hotels and airlines) because they can manage both capacity and customer duration. Other industries can shift to Quadrant 2 to achieve some of the revenue gains associated with RM by manipulating duration and prices.

Although travel agencies share similar characteristics with those in the tourism sectors under Quadrant 2, they may fall under Quadrant 1. Although the duration of customer use is predictable, the most widely used price structure is cost-based pricing, which differentiates travel agencies from traditional RM industries. The most common way to achieve a predictable duration is to pre-set a brochure price and communicate it to everyone who purchases inclusive packages. Mark-up pricing is most commonly used in travel agencies, whereas airlines and hotels offer different fares to match market needs. Travel agencies can forecast demand based on holidays. If travel agencies can adopt demand-based pricing, then logically they may be able to position themselves in Quadrant 2 and be as successful as other traditional RM industries.

\subsubsection{RM Typology: Nontraditional RM}

RM in traditional RM industries can be used and extended to other nontraditional RM industries such as restaurants, heritage sites, tourist attractions, ski resorts, golf clubs, cruise industries, resorts, casinos, theme parks and healthcare facilities. All of these industries have the potential to apply RM. Although travel agencies share characteristics with traditional and nontraditional RM industries, they also provide significant services in their business operations. A travel agency typically acquires, bundles (air tickets, hotel, food and beverages and excursions) and then markets and sells services to customers.

Tourism products are mostly perishable inventory, and thus, proper inventory control could determine whether rooms or seats can be sold in advance based on demand forecasting, correct pricing structures, proper market segmentation or advance reservations. Therefore, the main objective of large travel agencies is to limit unsold packages (i.e., unsold rooms in their contractual agreement).

To understand RM's constructs, Table 2 presents a modified typology of RM management according to flexibility capacity, duration of service use, physical constraints for identification by different services user and different pricing strategies. 
Table 2. Typology modification of RM industries

\begin{tabular}{|c|c|c|c|c|}
\hline \multirow[t]{2}{*}{ Industry examples } & \multirow{2}{*}{$\begin{array}{l}\text { Traditional RM } \\
\text { industries } \\
\text { Hotels and } \\
\text { Airlines } \\
\end{array}$} & \multicolumn{2}{|c|}{ Nontraditional RM industries } & \multirow{2}{*}{$\begin{array}{l}\text { Potential } \\
\text { nontraditional RM industries } \\
\text { Travel Agencies }\end{array}$} \\
\hline & & $\begin{array}{l}\text { Restaurant } \\
\text { Gold Clubs }\end{array}$ & $\begin{array}{l}\text { Theme Parks and } \\
\text { Tourism Attractions }\end{array}$ & \\
\hline Service capacity & Fixed & $\begin{array}{l}\text { Relatively } \\
\text { fixed }\end{array}$ & Relatively flexible & Relatively flexible \\
\hline Duration of service use & Fixed & Variable & Variable & Fixed \\
\hline Physical constraint & Very constrained & $\begin{array}{l}\text { Constrained but } \\
\text { elastic }\end{array}$ & $\begin{array}{l}\text { No constraints and } \\
\text { elastic }\end{array}$ & $\begin{array}{l}\text { Constrained by the availability } \\
\text { of product/service supplier }\end{array}$ \\
\hline Pricing & \multicolumn{3}{|c|}{ Demand-based pricing } & Cost-based pricing \\
\hline
\end{tabular}

Source: Adapted from Heo and Lee (2009, p. 118).

\subsubsection{Service Capacity}

Traditional RM industries such as airlines and hotels are limited in terms of their service capacity. A number of nontraditional RM industries, such as golf club restaurants, have similarly limited service capacity, whereas others are relatively flexible, such as theme parks, tourism attractions and travel agencies.

When a travel agency blocks 30 full-risk rooms from a hotel at a specified price upon arrival, the agency is fully responsible for this room block and should therefore manage the prepaid rooms and reduce wasted rooms, that is, minimize the costs of the hotel rooms sold as part of packaged vacations. Given the primary goal of selling all of the blocked rooms as quickly as possible (or at least of removing the risk from the books as soon as possible), the objective is to achieve minimum spoilage or unsellable risk rooms (Anderson \& Xie, 2009). With regard to this primary goal, travel agencies should use all of the full-risk rooms that are sold.

However, travel agencies that use inventory control are not limited to selling risk rooms because they have additional contractual agreements with different hotel suppliers such that many rooms are available at a particular hotel on the spot or on a non-risk basis. These non-risk rooms can be used because customers do not know whether they are staying in risk (blocked) or non-risk (contracted rate) rooms. Thus, the strategies of large travel agencies in terms of service capacity should be to simultaneously allocate and manage risk and non-risk rooms for the entire season. Meanwhile, non-risk rooms can be made available for purchase at a contracted rate. As a result, the booking volume of non-risk rooms can be extended from different suppliers and adjusted to a saturated level, allowing travel agencies to offer more package tours to fulfill market needs.

\subsubsection{Duration of Service Use}

Traditional RM industries are limited by their booking periods and physical constraints, whereas travel agencies are limited only by booking periods during holidays such as Christmas, Easter or Chinese New Year. Therefore, travel agencies require full payment when reservations are made to protect their revenues. The duration of service use in the travel industry is more likely to be fixed during particular holidays, and many customers limit the purchase of packages during the holidays, so travel agencies must use different holidays to design products that attract high-spending customers.

Nontraditional RM industries such as theme parks, tourism attractions, restaurants and golf clubs have service durations that can be purchased at any time on any day and are not limited to any season or holiday. Nontraditional RM industries have more flexibility in the duration of service use, and thus have great potential to integrate RM.

\subsubsection{Physical Constraints}

Compared with traditional RM industries, travel agencies have features that are similar to those of theme parks or tourist attractions, which offer flexible capacity. Airlines and hotels cannot add more seats or rooms during their peak demand because they have limited capacity.

However, the physical constraints of travel agencies are characterized by seasonality. Because travel agencies do not own their end products, they are constrained by the availability of products or offers from the service suppliers. During high seasons, travel agencies mirror traditional RM industries in that their capacity is very constrained by the offerings from hotels and airlines, whereas in low seasons, there is less demand and thus fewer constraints on capacity.

Restaurants, golf clubs and similar establishments are limited by physical constraints, and their pricing is 
considered elastic. Travel agencies can sell various tourism products according to their contractual agreements with different suppliers. This provides the travel agencies with an opportunity to extend their relatively flexible service capacity because they can accept more reservations, which leads to higher profits.

\subsubsection{Pricing}

Compared with both traditional and nontraditional RM industries, travel agencies provide special features in their pricing strategies, often using cost- rather than demand-based product pricing. Travel agency pricing involves mark-up strategies and selling price adjustments. Traditional and nontraditional RM industries adjust prices based on demand forecasting, using demand-based pricing, high-demand-high-price and low-demand-low-price concepts to increase their revenue.

Studies have shown that dynamic pricing is not new to travel agencies. The early adoption of dynamic pricing and the use of complex RM management decisions in travel agencies was highlighted by Holloway and Robinson in 1995 (Ingold et al., 2000). Price setting for RM was adopted early on by Robinson, who was the group marketing manager of First Choice, Britain's leading tour operator. Their brochure price was set, but a policy was proposed to offer early booking discounts, child discounts and late sales reductions to gain market shares and achieve an overall price advantage (Ingold et al., 2000).

Travel agencies may consider using dynamic pricing to design package prices or sell package tours at the highest rates possible during peak demand seasons to achieve revenue optimization. Adjusting pricing approaches improves market share and overall price advantage. Small and medium-sized enterprises such as Hong Kong travel agencies may encounter multiple barriers to successful RM implementation, such as lack of resources, different pricing strategies, or the constraints of the intermediary role. Therefore, RM may be relevant for travel agencies in improving the business operation.

\subsection{A Critique of the RM Literature}

Two previous studies conducted in Canada (Anderson \& Xie, 2009; Marcus \& Anderson, 2008) have discussed the same case of RM in a travel agency. The studies focused mainly on North America under the assumption that all travel agencies could use the observed strategies (e.g., inventory allocation). Both studies highlighted the use of room-risk agreements by travel agencies to manage their packages and resell bundled vacations. Thus, the benefits, based on the inventory allocation demonstrated by these two studies, are relevant to Hong Kong's wholesalers and other large travel agencies.

Although previous studies have addressed how to use service capacity management and inventory allocation, information on adopting appropriate pricing strategies, predictable demand and market segmentation has been limited. RM is a comprehensive concept, and travel agencies must make use of its different aspects, such as how to segment the market, how to use pricing approaches to design their products, how to predict market demand and what types of strategies stimulate demand. Numerous issues must be considered beyond how to apply inventory allocation to their operations.

Previous research has not addressed certain issues in sufficient depth. Because previous studies have only examined a small minority of travel agencies, this study breaks new ground by examining different types of travel agencies in Hong Kong and the feasibility of applying RM under different conditions to restore the industry's credibility in Hong Kong.

\subsubsection{Difference in Operation Features}

Certain aspects of the situation in Hong Kong are more complex than those of the situation in North America. From an operational perspective, there are differences in the organizational cultures of Hong Kong and North America. Four types of agencies are typically found in North America: mega, regional, consortium and independent. Mega, regional and consortium agencies tend to be larger, whereas independent agencies are often smaller (Gee et al., 1997).

The majority of Hong Kong travel agencies are also privately or family-run SMEs (small and medium-size enterprises) with services limited to purchasing airline tickets and hotels. Regarding financial management, Hong Kong travel agencies often conduct business transactions in cash, whereas in the West, various types of payment are used. Moreover, Western agencies appear to enjoy spending and are less strict regarding cost control, whereas Hong Kong companies abhor spending and exercise tight cost control (Bjerke, 2000).

Structural differences have been found in the organizational cultures of Canadian and Hong Kong travel agencies. Hence, Hong Kong SME travel agencies may encounter barriers that constrain RM implementation that other countries may not encounter, such as the following. 
A lack of resources that may limit RM application. SME travel agencies cannot compete with large wholesalers because the latter have various contractual agreements with suppliers that small agencies lack, limiting their service capacity. In addition, a shortage of capital and resources can also limit IT development, increasing the difficulty of competing with large wholesalers and suppliers.

Previous studies have been limited to large travel agencies (e.g., Sunquest Vacations, a Canadian travel provider) and thus have not been representative of Hong Kong's travel agency industry as a whole. There is an urgent need for fundamental research on Hong Kong travel agencies so that knowledge on how to establish RM can be successfully adapted.

Cost-based pricing (mark-up strategies) has been widely adopted by Hong Kong travel agencies. Thus, it may be difficult to convince industry professionals to try different pricing strategies because many do not appear to be convinced of the feasibility of implementing RM in their business operations. The answers to these questions are meaningful for Hong Kong travel agencies, and therefore, they are systematically addressed in this study.

Finally, as intermediaries, travel agencies sell tourism products on behalf of different suppliers, which makes it difficult for them to control their inventory. Some companies are unable to change their capacity by adjusting the amounts of available space (Kimes, 1989). Restaurants can reconfigure their dining rooms or use outdoor seating during summer months. Although travel agencies can adjust their service capacity or allocate inventory according to their engagements with different suppliers, during peak demand, they still struggle to control their service capacity. To increase service capacity, it is advantageous to form good networks and relationships with suppliers.

\subsubsection{Guanxi between Suppliers and Travel Agencies}

Relationships between suppliers and travel agencies are a crucial element in their contractual agreements. Chinese culture's unique emphasis on guanxi (relationships or social connections based on mutual interests and benefits; Wang, 2007) affects the service capacity provided to travel agencies by suppliers. The formation of good relationships and strong networks is a key determinant of success among Hong Kong travel agencies. Strong connections allow them to acquire more contractual agreements with competitive rates, thereby increasing the quantity of hotel rooms or airline seats that they are given to sell in their packages. The development of guanxi networks can free businesses from relying strictly on the more familiar contract-based agreements (Standifird \& Marshall, 2000). Therefore, relationships are a hard-to-control factor that travel agencies incorporate into their service capacity.

Studies have shown that Hong Kong travel agencies face barriers in implementing RM in their businesses. Although there are many uncertainties, travel agencies can replicate some of the ideals and concepts from RM strategies, such as segmenting the market to forecast demand patterns and create demand, improving productivity.

As one of the few publications on RM implementation in travel agencies that focuses on industry professionals in Hong Kong as a target population, this study has significant implications for the industry as a whole. The application of RM in many hospitality industries has generally led to the finding that these industries can manage capacity or make use of different pricing structures, segment different markets, predict demand and fill reservations in advance. Traditional hospitality industries (e.g., airlines and hotels) can and do use RM in their businesses. Other nontraditional hospitality industries (e.g., theme parks, tourism attractions, cruise lines and restaurants) can outline their special characteristics and define suitable RM models for their business operations. To combat shrinking profits, travel agencies may consider applying RM in their businesses. Given their shared characteristics, travel agencies have the potential to modify and design the right RM models for their respective businesses.

This study should be of interest to industry professionals for its ability to stimulate awareness of RM application in travel agencies. To obtain a comprehensive view of the entire industry, corroborating evidence from a variety of methods is important. Productive results are expected if data are obtained from experts who have accumulated both operational and managerial experience from industry professionals.

\section{Methodology}

\subsection{Data Collection and Analysis}

This study adopted a descriptive research design using a qualitative approach. Hong Kong was chosen as the research site and industry professionals as the target respondents. Purposive samplings were adopted, and the target sample size was 10 industry practitioners. Respondents were drawn from different organizations including wholesalers, retail travel agencies, ticketing agencies, and multinational firms. 
The interview questions were based on Kimes' (1989) theoretical framework. The four questions used to guide this study are as follows:

- What are travel agencies' perceptions of RM?

- Can RM be implemented in Hong Kong travel agencies?

- What are the main barriers to this implementation?

- What factors might facilitate it?

Bilingual versions of the question list were produced in English and traditional Chinese using the back-translation method. The agenda for the interview and detailed list of questions were given to participants roughly two weeks prior to the interviews to allow them to reflect on the study's areas of concern.

The in-depth interviews took place in comfortable environments, and each interview averaged approximately one hour; each was audio recorded and fully transcribed. With permission, all interviews were recorded to expedite communication and facilitate post-interview analysis if necessary. Underlying the study both conceptually and methodologically is grounded theory, which harbors no preconceived notions about RM implementation in travel agencies but allows for theory to emerge from the interview data as they are systematically collected and analyzed (Glaser, 1998). Grounded theory methods yield "thick description" of the target topic, building the theory through a successive process of open coding as the interviews continue.

It is also crucial to monitor for theoretical saturation, which is the point when new interviews no longer yield new themes (McCracken, 1988). If the 10 scheduled interviews had not produced theoretical saturation, the authors were prepared to identify additional candidate. In fact, however, no new themes emerged after the 10 interviews were completed.

The audio recordings of each interview were transcribed into traditional Chinese and then translated into English. A summary form was completed after each interview to record the information given to each participant, summarize the interview content, and provide a reference point for the next interview. The information collected were numbered and recorded in a summary document. Notes and memos will also be written up from the beginning of the data collection period.

The data analysis and coding were conducted in multiple stages. The codes were generated and displayed in different categories (such as different types of travel professionals) in themed charts. Domain analysis was used to describe and analyze each theme separately. The findings at different levels were then synthesized, and the coding results at different levels were compared to explore differences in opinions and suggestions.

This study incorporates primary as well as secondary data and provides research findings. The first stage of this study adopted in-depth interviews with ten travel professionals. Interviews lasted between 45 minutes and 1 hour, an appropriate length of time (Maxwell, 2005).

Table 3. Interviewee profiles

\begin{tabular}{|c|c|c|c|c|c|c|c|c|c|}
\hline Code & Position & $\begin{array}{l}\text { Working } \\
\text { Experience } \\
\text { (Year) }\end{array}$ & Sex & Age & Education & $\begin{array}{l}\text { Form } \\
\text { of } \\
\text { organization }\end{array}$ & $\begin{array}{l}\text { Size } \\
\text { Of } \\
\text { unit }\end{array}$ & $\begin{array}{l}\text { Know RM } \\
\text { Concept }\end{array}$ & $\begin{array}{l}\text { Competency } \\
\text { of } \\
\text { RM } \\
\text { application }\end{array}$ \\
\hline PR1 & $\begin{array}{l}\text { Sales and } \\
\text { Marketing } \\
\text { Manager }\end{array}$ & 8 & $\mathrm{~F}$ & $35-45$ & $\begin{array}{l}\text { Bachelors } \\
\text { Degree }\end{array}$ & $\begin{array}{l}\text { Retail Travel } \\
\text { Agency }\end{array}$ & $\begin{array}{l}80 \\
\text { employees }\end{array}$ & No & Yes \\
\hline PM2 & $\begin{array}{l}\text { Project } \\
\text { Manager }\end{array}$ & 25 & F & $45-55$ & $\begin{array}{l}\text { Diploma } \\
\text { Level }\end{array}$ & $\begin{array}{l}\text { Multinational } \\
\text { Travel Agency }\end{array}$ & $\begin{array}{l}\text { Over } 1000 \\
\text { employees }\end{array}$ & Yes & Yes \\
\hline PM3 & $\begin{array}{l}\text { Sales and } \\
\text { Marketing } \\
\text { Manager }\end{array}$ & 15 & M & $45-55$ & $\begin{array}{l}\text { High } \\
\text { School }\end{array}$ & $\begin{array}{l}\text { Multinational } \\
\text { Travel Agency }\end{array}$ & $\begin{array}{l}800 \\
\text { employees }\end{array}$ & No & Not sure \\
\hline PW4 & $\begin{array}{l}\text { General } \\
\text { Manager }\end{array}$ & 25 & M & $45-55$ & $\begin{array}{l}\text { Master } \\
\text { Degree }\end{array}$ & $\begin{array}{l}\text { Multinational } \\
\text { Travel Agency }\end{array}$ & $\begin{array}{l}500 \\
\text { employees }\end{array}$ & Yes & Yes \\
\hline PR5 & $\begin{array}{l}\text { General } \\
\text { Manager }\end{array}$ & 20 & M & $35-45$ & $\begin{array}{l}\text { Master } \\
\text { Degree }\end{array}$ & $\begin{array}{l}\text { Wholesalers } \\
\text { Travel Agency }\end{array}$ & $\begin{array}{l}700 \\
\text { employees }\end{array}$ & Yes & Yes \\
\hline PR6 & $\begin{array}{l}\text { General } \\
\text { Manager }\end{array}$ & 30 & M & $55-65$ & $\begin{array}{l}\text { Master } \\
\text { Degree }\end{array}$ & $\begin{array}{l}\text { Retail Travel } \\
\text { Agency }\end{array}$ & $\begin{array}{l}300 \\
\text { employees }\end{array}$ & No & Yes \\
\hline
\end{tabular}




\begin{tabular}{|c|c|c|c|c|c|c|c|c|c|}
\hline PT7 & $\begin{array}{l}\text { General } \\
\text { Manager }\end{array}$ & 30 & $\mathrm{M}$ & $55-65$ & $\begin{array}{l}\text { Master } \\
\text { Degree }\end{array}$ & $\begin{array}{l}\text { Ticketing } \\
\text { Travel Agencies }\end{array}$ & $\begin{array}{l}400 \\
\text { employees }\end{array}$ & No & Yes \\
\hline PR8 & $\begin{array}{l}\text { Sales and } \\
\text { Marketing } \\
\text { Manager }\end{array}$ & 10 & $\mathrm{~F}$ & $45-55$ & $\begin{array}{l}\text { Bachelors } \\
\text { Degree }\end{array}$ & $\begin{array}{l}\text { Retail Travel } \\
\text { Agency }\end{array}$ & $\begin{array}{l}80 \\
\text { employees }\end{array}$ & No & Yes \\
\hline PR9 & $\begin{array}{l}\text { Branch } \\
\text { Manager }\end{array}$ & 20 & $\mathrm{~F}$ & $55-65$ & $\begin{array}{l}\text { High } \\
\text { school }\end{array}$ & $\begin{array}{l}\text { Retail Travel } \\
\text { Agency }\end{array}$ & $\begin{array}{l}150 \\
\text { employees }\end{array}$ & No & Yes \\
\hline PM10 & $\begin{array}{l}\text { Regional } \\
\text { Director }\end{array}$ & 30 & $\mathrm{~F}$ & $55-65$ & $\begin{array}{l}\text { High } \\
\text { School }\end{array}$ & $\begin{array}{l}\text { Multinational } \\
\text { Travel Agency }\end{array}$ & $\begin{array}{l}200 \\
\text { employees }\end{array}$ & No & Not sure \\
\hline
\end{tabular}

Interviewees were from various organizational backgrounds (Table 3) and comprised five female and five male travel professionals. The interviewees had solid industry backgrounds ranging from 8 to 30 years of work experience. They also had different education levels ranging from secondary school to master's degrees. The interviewees were responsible for sales and marketing, operations and general management. The related organizations employ from 80 to over 1000 employees in general. The organizations, from medium to large in size, provide a very wide range of travel services in Hong Kong and worldwide.

\section{Result and Discussion}

Only 3 interviewees among the 10 demonstrated understanding of RM, and all demonstrated limited knowledge of or misunderstanding about RM. 2 interviewees were unsure, but 8 interviewees claimed that travel agencies in Hong Kong could competently apply RM in business operations.

\subsection{Perceptions of Travel Agencies' RM Practices}

Most of the respondents were uncertain about the current trading environment and concerned about the business implications of suppliers' intervention. They saw the use of different e-channels as leading to price transparency and enabling competitive advantage in their business settings. 8 of the respondents generally thought that agencies that could successfully implement RM would be more likely to improve profits. Their understanding of RM was minimal and focused narrowly on profit maximization. Large numbers of travel agencies have not applied RM methods in their businesses because of this low level of awareness and limited knowledge. The findings also showed that many travel practitioners have a limited conceptual understanding of RM.

\subsection{The Possibility of Implementing RM in Hong Kong Travel Agencies}

All of the respondents agreed that RM implementation was a practical option and that their businesses had the competence required to achieve it as part of business operations. They felt that such implementation would be an effective way to increase profits. Most of the interviewees were confident that Hong Kong travel agencies had the capacity to implement RM in their operations. Eight interviewees confirmed that travel agencies have the potential to shift from Quadrant 1 to Quadrant 2 (see Table 4), that is, to be as successful as traditional and nontraditional RM industries.

Table 4. Typical pricing and duration positioning of travel agencies

\begin{tabular}{|c|c|c|c|}
\hline & & \multicolumn{2}{|c|}{ Price } \\
\hline & & Fixed & Variable \\
\hline \multirow{10}{*}{ Duration } & \multirow{6}{*}{ Predictable } & Quadrant 1 & Quadrant 2 \\
\hline & & Cinemas & Hotels \\
\hline & & Showplaces & Airlines \\
\hline & & Stadiums & Rental cars \\
\hline & & Convention centers & Cruise lines \\
\hline & & & Travel Agencies \\
\hline & \multirow{4}{*}{ Unpredictable } & Quadrant 3 & Quadrant 4 \\
\hline & & Restaurants & Continuing care \\
\hline & & Golf courses & Hospitals \\
\hline & & Internet service & \\
\hline
\end{tabular}

Source: Adopted from Kimes (1989).

A number of industries offer special combinations of duration control and variable pricing. Successful industries are found in Quadrant 2 because they can manage both price and customer duration. Responses from interviewees suggest that travel agencies were competent to manage their capacity and customer durations. 
Furthermore, most customer demand for tourism products is predictable, and therefore, travel agencies can potentially shift from Quadrant 1 to Quadrant 2 to achieve the revenue gains associated with RM by manipulating the duration and prices. Evidence from all interviewees showed that travel professionals agreed that travel agencies could possibly land in Quadrant 2.

\subsection{Barriers to Implementing RM}

Five barriers to implementing RM in Hong Kong travel agencies were identified in this study. Most of the respondents thought that the major barrier was travel agencies' lack of ownership of their inventory. Because they did not control their products, they were subject to constant uncertainty in business operations. Time pressure was another concern, in terms of responding to last-minute discounts offered by suppliers. The respondents reported that it was extremely difficult to adjust prices or deploy sales tactics to shift unsold volume as departure dates approached. This was the case even when reduced price offers were available. They also commented that the possibility of implementing RM depended on organizational structure. Larger organizations with sufficient capital could have an advantage over small travel agencies. Others thought that a lack of human resources and expertise might also present barriers to successful implementation.

\subsection{Facilitators of RM Implementation}

Although there are many barriers to RM implementation, many interviewees thought that enhancing their own RM knowledge and understanding was an essential step, and they cited relevant pricing knowledge and good information systems as among the necessary ingredients for enhancing firms' RM know-how in firms. The respondents also identified capacity control and adequate contract management as crucial aspects of operations. They particularly highlighted the benefits of good contact management, which they saw as creating more bargaining power and flexible control of capacity.

The respondents noted the importance of adopting dynamic pricing to stimulate market demand and maximize profits. Pricing strategies can target customers across various periods (such as high or low seasons), align with seasonal price bandings, charge different prices and generally use different product and pricing strategies for different groups of guests. Another approach is to design unique products such as tailor-made trips, offer more choices and add value to the product offering by including multiple rates. All of these strategies may provide an advantage when implementing RM.

Other aspects were also highlighted as facilitative, such as predictable demand and improved technology. An additional insight from this study is the importance of maintaining good relationships with suppliers to gain an advantage in capacity management. Travel agencies who do this can extend their capacity to cater to customers' needs during different periods of seasonal demand. The respondents also suggested that larger organizations would have more potential to deploy RM because they have the necessary resources. Relevant marketing strategies were also thought to improve the chances of successful RM use.

Overall, these recommendations give rise to a series of preliminary suggestions, as set out here. It is clear that the successful implementation of RM in travel agencies involves a focus on the basic principles of time and pricing structure control.

\section{Conclusion and Implications}

The findings of this study suggest a number of practical implications for practitioners. Travel agencies should understand their barriers and facilitators and make use of RM for profit optimization. Travel agencies can provide flexible capacity; increase customer product choices and increase business opportunities; offer limited discounts during peak seasons; and charge premium prices to increase revenue while providing low-season discounts to retain customers as a way of maximizing profits. It was determined that practitioners had to understand and predict demand patterns and create promotional events to stimulate sales and business and use of segmentable market strategies, including widening the segment base and applying different marketing strategies to reach more potential customers. With an online reservation system connected to an RM system, travel agencies can increase customer satisfaction and provide updated information (through the Internet, customers can make reservations at any time, and the agency can accommodate more inquiries, eliminating concerns about disintermediation and reduced commissions from airlines and hotels), implementing dynamic pricing and regaining market share. Travel agencies need to use RevPATP to optimize profits and need to manage strategic leverage based on time, pricing and product when designing their products. Thereby, travel agencies can be as successful as other traditional and nontraditional RM industries.

There are a few areas that are open for future research. One extension of this study is to repeat the research but with greater geographic coverage, for a longer period of time and with more different types of travel agencies. 
This will offer a more comprehensive examination of how travel agencies in different regions apply RM. Future studies can also investigate the relationship between suppliers and travel agencies as an interest in capacity management.

\section{References}

Anderson, C. K., \& Xie, X. (2009). Room-risk management at Sunquest vacations. Cornell Hospitality Quarterly, 50(3), 314-324. http://dx.doi.org/10.1177/1938965509336064.

Barnett, M., \& Standing, C. (2000). Repositioning travel agencies on the internet. Journal of Vacation Marketing, 7(2), 143-152. http://dx.doi.org/10.1177/135676670100700204

Berman, B. (2005). Applying yield management pricing to your service business. Business Horizons, 48(2), 169-179. http://dx.doi.org/10.1016/j.bushor.2004.10.015

Bjerke, B. V. (2000). A typified, culture-based, interpretation of management of SMEs in Southeast Asia. Asia Pacific Journal of Management, 17, 103-132. http://dx.doi.org/10.1023/A:1015441021413

Chiang, W. C, Chen, J., \& Xu, X. (2007). An overview of research on revenue management: current issues and future research. International Journal of Revenue Management, 1(1), 97-128. http://dx.doi.org/10.1504/IJRM.2007.011196

Cross, R. L. (1997). Revenue Management. New York, NY: Broadway Publishing House.

Gee, C. H., Makens, J. C., \& Choy. J. L. (1997). The Travel Industry. New York, NY: John Wiley \& Sons, Inc.

Glaser, B. (1998). Doing Grounded Theory: Issue and Discussion. Mill Valley, CA: Sociology Press.

Heo, C. Y., \& Lee, S. (2009). Application of revenue management practices to the theme park industry. International Journal of Hospitality Management, $28(3), \quad 446-\quad 453$. http://dx.doi.org/10.1016/j.ijhm.2009.02.001

Hermes Management Consulting. (2008). Understanding Travel Agency Cost Drivers and Ways to Optimize Business in Online Travel Agencies.

Hong Kong Tourism Board press release: Tourism arrival information in 2012. (Accessed Mar. 30, 2014).

Ingold, A., McMahon-Beattie, U., \& Yeoman, I. (2000). Yield Management Strategies for the Service Industries (2nd ed.). London: Continuum.

Kimes, S. E. (1989). Yield management: a tool for capacity-considered service firms. Journal of Operations Management, 8(4), 348-363. http://dx.doi.org/10.1016/0272-6963(89)90035-1

Kimes, S. E. (2000). Revenue Management on the links: applying yield management to the golf-course industry. Cornell Hotel and Restaurant Administration Quarterly, 41(1), 120-127. http://dx.doi.org/10.1016/S0010-8804(00)88891-6

Kimes, S. E., \& Singh, S. (2009). Spa Revenue Management. Cornell Hospitality Quarterly, 50, 82-85.

Kimes, S. E., Chase, R. B., \& Lee, P. Y. (1998). Restaurant revenue management: Applying yield management to the restaurant industry. Cornell Hotel and Restaurant Administration Quarterly, 39(3), 32-39. http://dx.doi.org/10.1177/001088049803900308

Law, R., \& Wong, J. (2003). Successful factors for a travel web site: Perceptions of on-line purchasers in Hong Kong. Journal of Hospitality \& Tourism Research, 27(1), 118-124. http://dx.doi.org/10.1177/1096348002238884

Law, R., Law, A., \& Wai, E. (2001). The impact of the internet on travel agencies in Hong Kong. Journal of Travel and Tourism Marketing, 11, 105-126.

Marcus, B., \& Anderson, C. K. (2008). Revenue management for low-cost providers. European Journal of Operational Research, 188(1), 258-272. http://dx.doi.org/10.1016/j.ejor.2007.04.010

Maxwell, J. A. (2005). Qualitative Research Design: An Interactive Approach. Thousand Oaks, CA: Sage Publications.

McCracken, G. (1988). The Long Interview. London: Sage Publishing House.

Minimum Wage Commission. (2012). Report of Minimum Wage Commission.

Noone, B. M., \& Mattila, A. S. (2009). Hotel revenue management and the internet: The effect of price presentation strategies on customers' willingness to book. International Journal of Hospitality Management 
28(2), 272-279. http://dx.doi.org/10.1016/j.ijhm.2008.09.004

Pak, K., \& Piersma, N. (2002). Airline revenue management: An overview of OR techniques 1982-2001. Econometric Institute Report EI 2002-03.

Standifird, S., \& Marshall, R. (2000).The transaction cost advantage of guanxi-based business practices. Journal of World Business, 35, 21-42. http://dx.doi.org/10.1016/S1090-9516(99)00032-2

Sun, X., Jiao, Y., \& Tian, P. (2011). Marketing research and revenue optimization for the cruise industry: A concise review. International Journal of Hospitality Management, 30(3), 746-755. http://dx.doi.org/10.1016/j.ijhm.2010.11.007

Travel Agents Registry. (2012). Hong Kong Special Administrative Region. Retrieved from http://www.tar.gov.hk/text/eng/about/major.html

Upchurch, R. S., Ellis, T., \& Seo, J. (2002). Revenue management underpinnings: An exploratory review. $\begin{array}{lllll}\text { International Journal of Hospitality } & \text { Management, } & \text { 21(1), } & \text { 67-83. }\end{array}$ http://dx.doi.org/10.1016/S0278-4319(01)00027-5

Wang, C. L. (2007). Guanxi vs. relationship marketing: Exploring underlying difference. Industrial Marketing Management, 36, 81-86. http://dx.doi.org/10.1016/j.indmarman.2005.08.002

Wardell, D. J. (1998). The impact of electronic distribution on travel agents. Travel and Tourism Analyst, 2 , 41-55.

Yeoman, I., \& Ingold, A. (1997). Yield Management Strategies for the Service Industries. London: Cassell Education Ltd.

\section{Copyrights}

Copyright for this article is retained by the author(s), with first publication rights granted to the journal.

This is an open-access article distributed under the terms and conditions of the Creative Commons Attribution license (http://creativecommons.org/licenses/by/3.0/). 